See Article page XXX.

\section{Commentary: An ounce of prevention, but an ounce of what?}

Peter D. Drevets, MD, ${ }^{\mathrm{a}}$ and

Richard Lee, MD, JD, MBA ${ }^{\mathrm{b}}$

Sternal wound infections are an unfortunate reality in cardiac surgery. As surgeons, we all believe an ounce of prevention is worth a pound of cure. When it comes to sternal infection, the question remains "an ounce of what?" In this edition of the Journal, Gaudino and colleagues ${ }^{1}$ present the results of their analysis to determine the association between sternal wound infection and longterm mortality.

The authors use the 3102 patients included in the Arterial Revascularization Trial (ART) for their study population. In comparing mortality at 5- and 10-year intervals, they found that those with sternal wound complications in the postoperative period had significantly greater mortality than those who did not have sternal wound complications. Following multivariate analysis, the authors concluded that sternal wound complications are independently associated with increased long-term mortality.

Sternal wound complications are known to decrease 1-year survival. ${ }^{2}$ In this analysis of the ARTS trial, Gaudino and colleagues ${ }^{1}$ reaffirm these findings and demonstrate that increased mortality is conserved over 5- and 10-year intervals. This analysis falls short in several areas. First, the ultimate cause of mortality is not defined. Without discrete data on cause of death, one cannot determine whether the ultimate etiology of death resulted from risk factors associated with sternal wound infection as opposed to the infection itself. For example, a patient with obesity, diabetes,

\footnotetext{
From the ${ }^{\mathrm{a}}$ Department of Surgery and ${ }^{\mathrm{b}}$ Division of Cardiothoracic Surgery, Medical College of Georgia, Augusta University, Augusta, Ga.

Disclosures: The authors reported no conflicts of interest.

The Journal policy requires editors and reviewers to disclose conflicts of interest and to decline handling or reviewing manuscripts for which they may have a conflict of interest. The editors and reviewers of this article have no conflicts of interest.

Received for publication Nov 26, 2021; revisions received Nov 26, 2021; accepted for publication Nov 30, 2021

Address for reprints: Richard Lee, MD, JD, MBA, Division of Cardiothoracic Surgery, Augusta University, 1120 15th St BA-4300, Augusta, GA 30912 (E-mail: ricklee@augusta.edu).

J Thorac Cardiovasc Surg 2021; $\mathbf{\square}: 1-2$ 0022-5223/\$36.00

Copyright $(2021$ Published by Elsevier Inc. on behalf of The American Association for Thoracic Surgery

https://doi.org/10.1016/j.jtcvs.2021.11.072
}

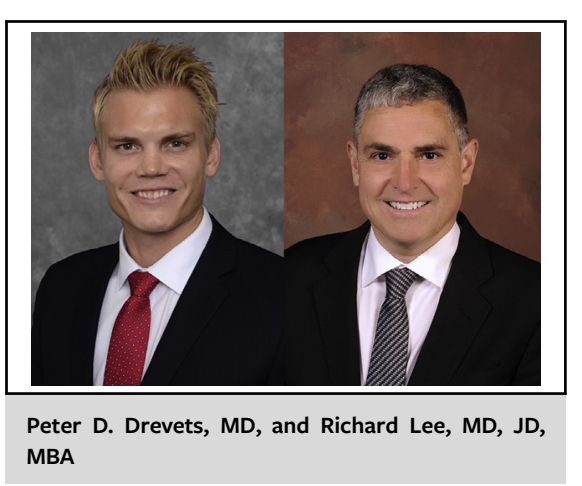

CENTRAL MESSAGE

Sternal wound infections are linked to long-term mortality. Future studies should better define how to prevent sternal wound complications more effectively.

and existing cerebrovascular disease will likely have decreased survival over a 10 -year period. The fact that the patient developed a wound infection postoperatively may be incidental to the ultimate cause of death.

Second, the risk factors most influential in causing infection are not defined. Identifying exactly which risk factors contribute the most risk for sternal wound complications is the next step. Blanket statements of association between sternal wound infections and increased mortality may be technically correct but ultimately stop short of truly defining the problem. Data on perioperative practices such as antibiotic choice and dosing, preparation technique, and method of sternal closure would add much to the analysis. Unfortunately, as the authors acknowledge, the ARTS data do not include these perioperative practices. Third, the data presented do not support an association between skeletonization of the mammary during harvesting and decreased rate of sternal wound infections. Conclusions regarding skeletonization are challenging with the reported data and should be cautiously presented. In addition, although we routine skeletonize the internal mammary artery, recent post hoc analysis of the COMPASS trial (Cardiovascular Outcomes for People Using Anticoagulation Strategies) suggested this may adversely impact patency. ${ }^{3}$

In conclusion, the authors present a thought-provoking analysis that defines avenues for future study on the 
prevention of sternal wound complications. The key to successful management of sternal wound infections is ultimately prevention. This requires successful definition of exactly what preventative measures can be taken to reduce risk as well as address the patient-specific risk factors that contribute most to wound complications. Although with limitations, the authors effectively convey the need to appreciate the devastating effect of sternal infection and, most importantly, the need for effective prevention.

\section{References}

1. Gaudino M, Audisio K, Rahouma M, et al. Association between sternal wound complications and 10-year mortality following coronary artery bypass grafting. J Thorac Cardiovasc Surg. XXX, 2021 [Epub ahead of print].

2. Sears ED, Wu L, Waljee JF, Momoh AO, Zhong L, Chung KC. The impact of deep sternal wound infection on mortality and resource utilization: a population-based study. World J Surg. 2016;40:2673-80. https://doi.org/10.1007/s00268-016-3598-7

3. Lamy A, Browne A, Sheth T, Zheng Z, Dagenais F, Noiseux N, et al; COMPASS Investigators. Skeletonized vs pedicled internal mammary artery graft harvesting in coronary artery bypass surgery: a post hoc analysis from the COMPASS trial [published correction appears in JAMA Cardiol. August 18, 2021]. JAMA Cardiol. 2021;6:1-8. https://doi.org/10.1001/jamacardio.2021.1686 